SISTEMA
ELETRÔNICO
DE REVISTAS
SER I UfPR

\title{
Implicações do modelo de ocupação da fronteira agrícola à agricultura familiar em Terra Nova do Norte e Nova Guarita, Amazônia mato-grossense
}

\section{Implications of the agricultural frontier occupation model for family farming in Terra Nova do Norte and Nova Guarita, Mato Grosso, Brazilian Amazon}

\author{
Marla WEIHS $^{1 *}$, Francis Junior Araújo LOPES ${ }^{1}$, Sara Mineli Caioni CARDOSO ${ }^{1}$, Anderson de Carvalho \\ CAMARGO ${ }^{1}$, Fernanda Oliveira $\mathrm{SILVA}^{2}$, Carolina Michels RUEDELL ${ }^{1}$ \\ ${ }^{1}$ Universidade do Estado do Mato Grosso (UNEMAT), Alta Floresta, MT, Brasil. \\ ${ }^{2}$ Instituto Federal do Mato Grosso (IFMT), Alta Floresta, MT, Brasil. \\ * E- para contato: marla@unemat.br
}

Artigo recebido em 7 de maio de 2019, versão final aceita em 7 de maio de 2020, publicado em 5 de agosto de 2020.

RESUMO: Este estudo objetiva compreender as dificuldades geradas pelo modelo de ocupação de uma fronteira agrícola da Amazônia brasileira e as estratégias usadas pelos agricultores familiares para superá-las. Os dados foram coletados por meio da realização de 20 grupos focais, associados à construção de linhas do tempo. Os desafios enfrentados pelos agricultores, durante a fase de ocupação agrícola do território, são similares aos vividos pelos milhares de brasileiros que migraram para a Amazônia em busca de terra e da reprodução social de suas famílias na agricultura. A exceção está na ocupação ilegítima de uma área de reserva legal coletiva, a qual gera restrições de acesso ao crédito rural, dadas as irregularidades fundiária e ambiental. Novas iniciativas de desenvolvimento emergem dos aprendizados assimilados durante as fases de crise e de reestabelecimento do setor da agricultura familiar na região.

Palavras-chave: Amazônia; fronteira agrícola; agricultura familiar.

ABSTRACT: This study aims to understand the difficulties generated by the occupation model of an agricultural frontier in the Brazilian Amazon and the strategies used by family farmers to overcome them. The data were collected through 20 focus groups, associated with the construction of timelines. The challenges faced by farmers 
during the phase of agricultural occupation of the territory are similar to those experienced by the thousands of Brazilians who migrated to the Amazon in search of land and the social reproduction of their families in agriculture. The exception is the illegitimate occupation of a collective legal reserve area, which generates restrictions on access to rural credit, given land and environmental irregularities. New development initiatives emerge from the lessons learned during the crisis and the reestablishment of the family farming sector in the region.

Keywords: Amazon; agricultural frontier; family farming.

\section{Introdução}

Desde o início da expansão da fronteira agrícola para o norte do estado de Mato Grosso, na década de 1970, uma parcela importante da floresta amazônica tem sido ilegalmente suprimida, degradada e fragmentada. Em alguns casos, até mesmo as reservas legais, destinadas à preservação da biodiversidade, foram abertas e transformadas em assentamentos rurais (Oliveira \& Bursztyn, 2005; Le Tourneau, 2016). Essa dinâmica de ocupação, sem ordenamento ou plano de gestão territorial, gerou problemas à agricultura familiar, que se desenrolam desde a fase inicial da expansão da fronteira agrícola, desencadeando tensões e conflitos (Escada et al., 2005; Schittini et al., 2012). Nos municípios Terra Nova do Norte e Nova Guarita essa problemática é antiga - e atual.

A ocupação agrícola de Terra Nova do Norte (TNN) e Nova Guarita (NG) data de 1978. O projeto inicial foi elaborado e executado por uma cooperativa, com suporte do Instituto Nacional de
Colonização e Reforma Agrária (INCRA), para atender a uma demanda do governo do Rio Grande do Sul. Em tempo recorde, foram assentadas cerca de 1.200 famílias de camponeses ${ }^{1}$ sem-terra. Grosso modo, cada uma dessas famílias teve acesso a 200 ha de terra, sendo que, dessa área, 100 ha foram destinados à agropecuária e os outros 100 ha à Reserva Legal, centralizada em um condomínio (Reserva Legal coletiva) (Castro et al., 2002; Santos, 2008). Falhas na execução do projeto e cortes de recursos federais colocaram em risco a permanência das famílias na terra. Em menos de dois anos, a maior parte delas havia comercializado a propriedade e migrado, em seguida, para os garimpos de ouro ou, na maioria dos casos, voltado para a sua região de origem.

No início da década de 1980, a notícia da disponibilidade de terra barata se espalhou pelo Brasil, atraindo centenas de camponeses para a região. As famílias com melhores condições financeiras adquiriram terras nas planícies em que haviam sido demarcadas as primeiras propriedades. As demais

\footnotetext{
${ }^{1}$ Adotamos o termo camponês quando nos referimos aos agricultores que saíram de sua região de origem, nas décadas de 1970 e 1980 , para ocupar terras na fronteira agrícola da Amazônia, onde inicialmente reproduziram seus modos de vida sem toda a gerência do Estado e do mercado observada nos dias de hoje (Oliveira, 1991; Sabourin, 2009; Wanderley, 2009). O termo agricultor familiar, por sua vez, é usado para definir os camponeses que sofreram mudanças socioprodutivas e culturais no período de transição do século XX para o XXI, as quais têm, como marco histórico, a criação do Programa Nacional de Fortalecimento da Agricultura Familiar (PRONAF), em 1995 (Wanderley, 2003 ). Como o uso das definições não pretende engessar os agricultores dentro de uma ou outra categoria social, na maior parte das vezes, usamos apenas o termo agricultor ou família de agricultor.
} 
famílias, com condições econômicas mais restritivas, ocuparam e demarcaram ou, na maior parte dos casos, adquiriram de terceiros, terras acidentadas e cobertas de matas, no interior do condomínio de reservas legais (Castro et al., 2002; ICV, 2015).

A ocupação irregular do condomínio de reservas legais e sua transformação em área agrícola gerou uma série de desafios à agricultura familiar, sobretudo em TNN. De uma parte, as famílias foram obrigadas a conviver com restrições de crédito, sobretudo no período mais recente. Essas restrições são determinadas, no caso das que possuem as reservas legais averbadas nas matrículas das propriedades, pela irregularidade ambiental, e, no caso das que ocupam o condomínio de reservas legais, pela irregularidade fundiária (ICV, 2015). De outra parte, a convivência pacífica dos dois grupos de agricultores vem sendo ameaçada por uma série de promessas políticas e processos jurídicos, que requerem a restituição das áreas de reservas legais aos agricultores que as possuem por direito (Castro et al., 2002).

Como esses problemas ameaçaram a agricultura familiar? Que estratégias foram e têm sido usadas pelas famílias para superar essas dificuldades? Sem o propósito de esgotar o assunto, propomo-nos a responder tais questões. O nosso objetivo é melhor compreender, de uma parte, as dificuldades geradas pelo modelo de ocupação da fronteira agrícola em TNN e NG, e, de outra, as estratégias usadas pelos agricultores familiares para superá-las. Trata-se de uma investigação de caráter participativo. Os dados foram coletados por meio da realização de 20 grupos focais de duração média de uma hora e meia, os quais eram orientados por um roteiro específico e acompanhados da construção de linhas do tempo.

\section{2. Área de Estudo}

Os municípios de TNN e NG estão localizados nas adjacências do quilômetro 700 da rodovia BR-163, Cuiabá-Santarém (Figura 1). Ambos são banhados pelos rios Teles Pires e Peixoto de Azevedo, da Bacia Amazônica. A vegetação natural é classificada como Floresta Ombrófila Aberta (IBGE, 2004) e, em 2017, o remanescente de floresta nativa correspondia a cerca de $15 \%$ (INPE, 2017). O solo da região é predominantemente argissolo vermelho-amarelo (EMBRAPA, 1999), tendo a pastagem como principal cobertura vegetal (IBGE, 2017a). O clima é o Aw, segundo Köppen, tropical chuvoso, com precipitação pluvial elevada (entre 2.500 a $2.750 \mathrm{~mm}$ ) e duas estações bem definidas: regime de chuvas, que se estende de novembro a março, com umidade relativa de $80,4 \%$; e período de seca, entre junho e agosto. A temperatura média anual é de $25,2^{\circ} \mathrm{C}$.

A população dos dois municípios totaliza 14.063 habitantes (IBGE, 2017a). Cerca de 58\% dela vive em situação rural (IBGE, 2010). Há forte predomínio da agricultura familiar em termos de número de estabelecimentos: $80 \%$ das propriedades caracterizam-se como empreendimentos familiares rurais, conforme definido pelo Decreto $\mathrm{n}^{\circ} 9.064$, de 31 de maio de 2017 (Brasil, 2017). Em termos de área, a agricultura familiar ocupa uma proporção marcadamente superior à estadual. Enquanto, em Mato Grosso, 9\% do território de ocupação agrícola destina-se à agricultura familiar, em TNN e NG, esse percentual é de $33 \%$ e $46 \%$, respectivamente (IBGE, 2017b).

Em ambos os municípios, a principal atividade econômica é a pecuária extensiva de corte e leite, 
cujo efetivo bovino total é de cerca de 415 mil cabeças ( $65 \%$ do total é produzido em TNN) (IBGE, 2017a). A produção de leite é a principal atividade econômica no setor da agricultura familiar, ultrapassando o volume anual de $34 \mathrm{mil} \mathrm{litros} /$ ano (TNN produz $85 \%$ desse volume) (IBGE, 2017a). Além disso, o setor produz abacaxi, arroz e mandioca, entre outros. $O$ volume da produção de abacaxi $(1,2$ milhões frutos/ano) coloca TNN em quarto lugar no ranking dos maiores produtores do estado. A expansão das lavouras de soja é recente nos dois municípios. O aumento da área plantada, entre os anos de 2012 e 2016, foi de 374\% em TNN e 169\% em NG (IBGE, 2017a).

\section{Desenho da Pesquisa e Itinerário de Campo}

O estudo baseia-se em resultados obtidos pelo projeto intitulado Implicações dos Ciclos da Fronteira Agrícola à Vida na Agricultura Familiar na Amazônia Mato-Grossense, desenvolvido por meio

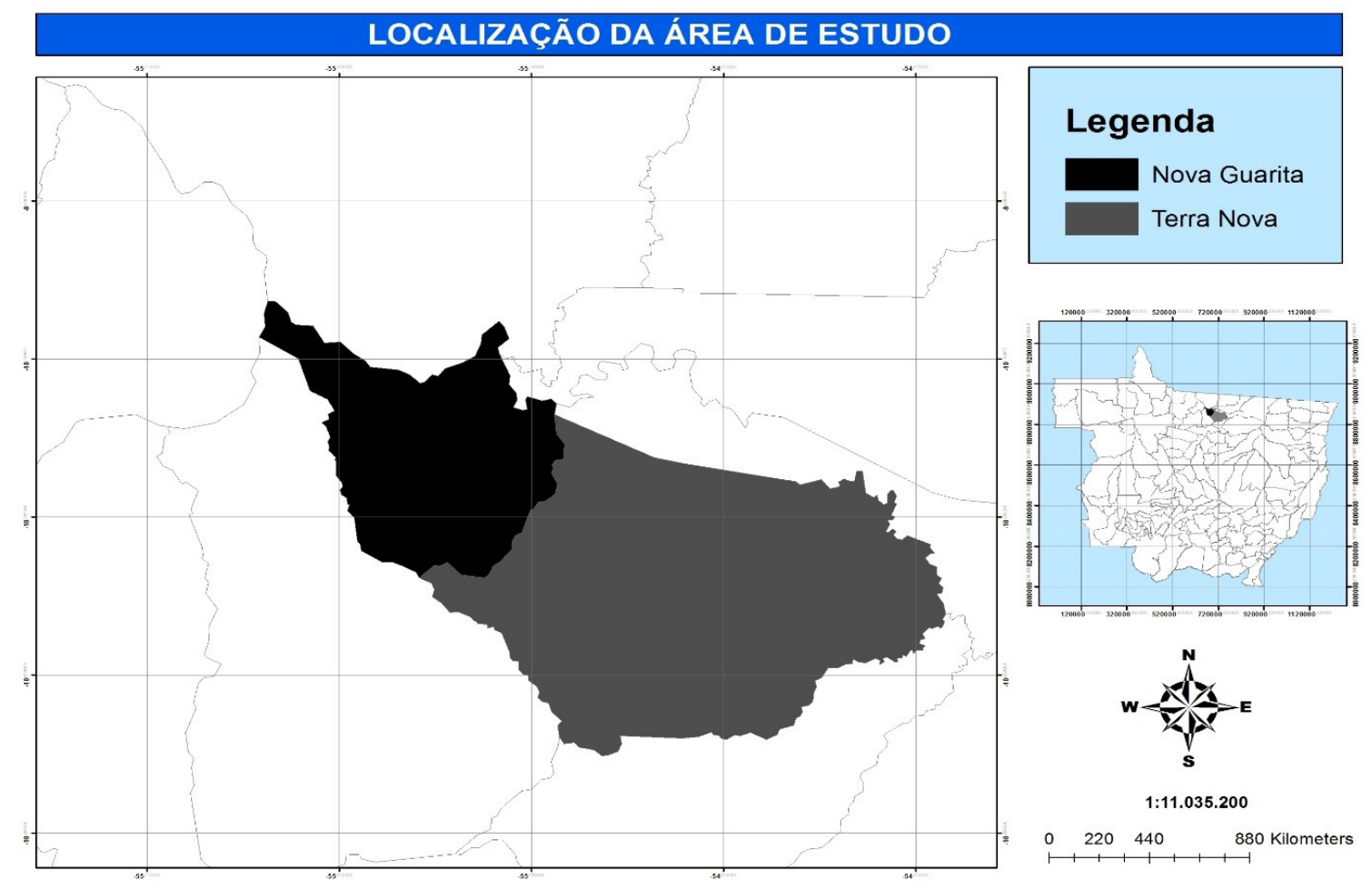

FIGURA 1 - Área de estudo.

FONTE: datum Sirgas 2000, IBGE (2000). Editado por Anderson Camargo no programa Arcgis 10.1. 
de uma parceria entre a Universidade do Estado de Mato Grosso (UNEMAT) e o Instituto Ouro Verde (IOV). Os recursos de custeio da pesquisa foram obtidos com o Banco Nacional de Desenvolvimento Econômico e Social (BNDES), responsável pela gestão do Fundo Amazônia. A pesquisa foi construída por meio da interação com pesquisadores e técnicos do grupo que integra o multi-institucional Programa de Pesquisa em Resiliência da Agricultura Familiar no Norte e Noroeste de Mato Grosso (PRAFAM).

O quadro metodológico da pesquisa é sustentado pelos princípios fundamentais da abordagem ecossistêmica: interdisciplinaridade e participação. Para atender aos requisitos da interdisciplinaridade, formou-se um grupo de especialistas constituído de três pesquisadores, das áreas das ciências biológicas e sociais, e três acadêmicos, bolsistas de iniciação científica. A partir de uma série de discussões internas, elaborou-se um roteiro de campo que embasou a realização de grupos focais (focal groups) (Weller, 2006; Trad, 2009) com 20 famílias de agricultores de Terra Nova e Guarita.

No que tange à participação dos interlocutores, privilegiou-se a constituição de grupos de dois a cinco participantes (familiares e vizinhos). A seleção dos participantes pautou-se em três critérios: (i) ter participado de uma das duas etapas do processo de ocupação agrícola da região, nos anos 1970 e 1980; (ii) autodenominar-se agricultor familiar; e (iii) participar (50\%) ou não participar (50\%) de movimentos sociais ou ações de desenvolvimento. $\mathrm{Na}$ medida do possível, foi ponderada a equidade de gênero e idade.

A condução dos grupos focais foi orientada por um roteiro de campo, o qual abordava: (i) as dificuldades que as famílias enfrentaram durante as fases do avanço da fronteira (agricultura, garimpo de ouro, pecuária e soja), bem como as estratégias que foram usadas para superá-las; e (ii) as ameaças/ dificuldades atuais e futuras com ênfase na expansão das lavouras de grãos (soja/milho) e na participação de movimentos sociais ou ações de desenvolvimento. A metodologia foi previamente testada com uma família de agricultores de Alta Floresta - MT.

Nos municípios de TNN e NG, as atividades ocorreram em propriedades rurais heterogeneamente distribuídas no território, no período de junho a agosto de 2017. Após a apresentação dos objetivos e metodologia da pesquisa, os participantes se organizavam em torno de uma mesa (Figura 2), sobre a qual eram dispostas duas cartolinas, coladas uma à outra, com o esboço inicial de uma linha do tempo, apresentando as fases do avanço da fronteira. Com uso do roteiro de campo, dois mediadores lançavam questões que incitavam uma discussão entre os membros da família.

As respostas eram sintetizadas na linha do tempo (timeline) por um terceiro integrante da equipe de pesquisa. Os grupos focais duraram entre uma a duas horas. Todas as conversas eram gravadas. Trechos dessas gravações foram transcritos e categorizados para análise e discussão de conteúdo

O grupo focal desloca o centro da coleta de dados do indivíduo para o coletivo. Dessa forma, a análise dos resultados, ao invés de ser pautada em narrativas individuais e no confrontamento das respostas dos indivíduos, sustenta-se no conjunto de acepções do grupo, que são interpretadas a partir dos consensos e dissensos manifestados durante as discussões (Gondim, 2003; Kitzinger, 2005). As linhas do tempo, por sua vez, sintetizam essas informações em eventos e marcos históricos, ampliando 
as possibilidades de apresentação e interpretação dos resultados (Yakura, 2002).

Os resultados foram discutidos pelo grupo de especialistas, de forma conjunta e participativa, objetivando uma compreensão sistêmica da problemática. Em uma fase posterior, a síntese desses resultados foi discutida com um grupo de cerca de 20 pesquisadores e técnicos, que participam do PRAFAM e, posteriormente, com um grupo de aproximadamente 300 agricultores, oriundos de mais de 12 municípios do norte de Mato Grosso, durante o IV Congresso de Agricultura Familiar realizado ente os dias 22 e 25 de março de 2018 , em Alta Floresta - MT. A oportunidade serviu para avaliar a consistência dos dados.
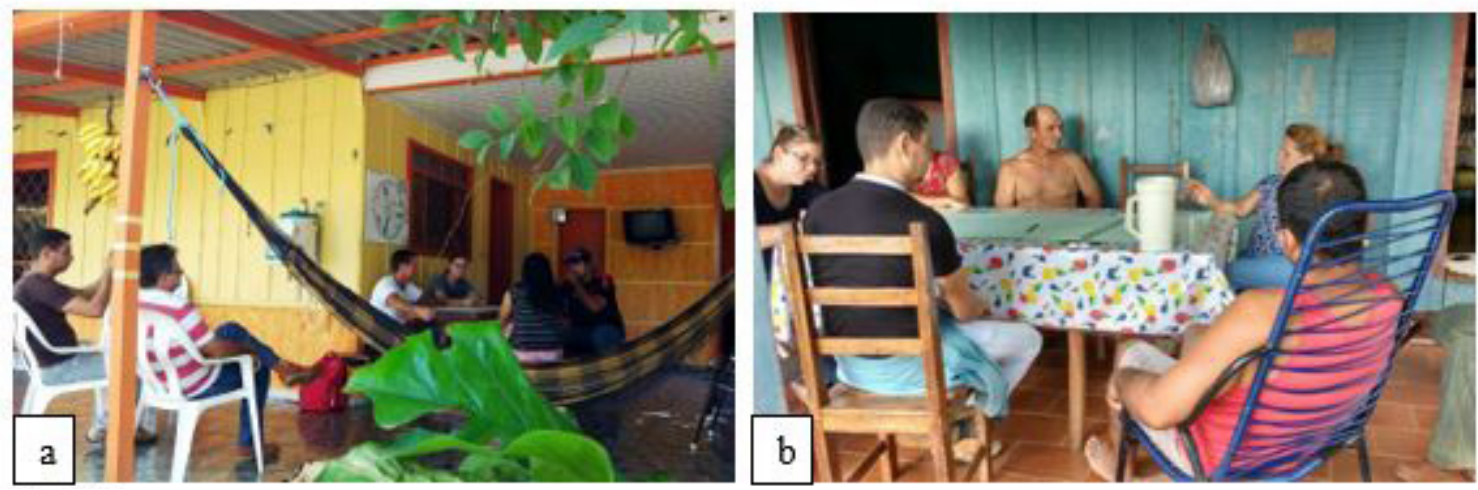

FIGURA 2 - Dinâmica dos grupos focais.

FONTE: Acervo pessoal dos autores.

${ }^{2}$ Trata-se de um modelo de produção baseado na invenção e disseminação de novas sementes e práticas agrícolas, melhoramento genético de sementes, uso intensivo de insumos industriais, mecanização e redução do custo de manejo. O objetivo final é o aumento da produtividade. As suas consequências sociais e ambientais são bastante criticadas, sobretudo no que diz respeito à marginalização de trabalhadores e as ameaças a ecossistemas e à saúde humana. 
À mesma época, o governo militar assumiu a integração econômica da Amazônia ao espaço nacional/internacional como estratégia de desenvolvimento. O território amazônico serviria de "válvula de escape" para aliviar as pressões sociais ligados à crescente concentração da terra nas outras regiões de domínio agrícola (Becker, 1988). Ademais, serviria para manter a região sob domínio brasileiro, tendo em vista uma série de discursos, proferidos em outros países e assimilados pelo governo federal, como ameaça à perda da soberania sobre esse território (Fearnside, 1984; Foucher, 1991). Em última instância, a criação de projetos de colonização da região teria sido motivada por interesses mercantis associados à expansão da agricultura mecanizada, agroindustrialização, urbanização e extrativismo (Franco da Silva \& Bampi, 2019).

De 1968, quando as primeiras iniciativas foram colocadas em curso, até os dias atuais, a expansão da fronteira trouxe um crescimento populacional monumental para a região (Browder et al., 2008). Em Mato Grosso, um dos estados de maior número de projetos de colonização, pelo menos 42 dos 141 municípios atuais foram criados, direta ou indiretamente, por empresas privadas de colonização (Arcemy, 2007). Somente na porção norte do estado, a população aumentou cerca de 12 vezes nas primeiras duas décadas de ocupação agrícola. De 60 mil habitantes, registrados no recenseamento do Instituto Brasileiro de Geografia e Estatística (IBGE) de 1970, a população passou para 710 mil na pesquisa de 1991 (Coy, 1996).

Os camponeses justificavam a migração para a Amazônia com as perspectivas de ampliação das propriedades agrícolas, fuga das intempéries do clima (seca e geada), melhoria das condições socioeconômicas e, principalmente, garantia da reprodução social da família na propriedade rural (Martins, 1997). As promessas das empresas e cooperativas de colonização convergiam com esses anseios. A Amazônia era apresentada como a solução dos problemas da época: risco de perda da autonomia econômica, êxodo rural e desemprego (Le Borgne-David, 1998).

Para atrair os camponeses, as empresas colonizadoras estruturaram escritórios na região Sul do país, montaram equipes que distribuíam panfletos e anunciavam, em programas de rádio, reuniões e visitas domiciliares, as vantagens de reiniciar a vida na Amazônia (Schwantes, 1989; Guimarães Neto, 2002). Assim, corria o país a notícia das vastas terras férteis da Amazônia, as facilidades de aquisição de uma propriedade, o baixo preço, a "alta" fertilidade do solo e as boas condições climáticas para a produção agrícola (Joanoni Neto, 2007).

Um dos primeiros grupos empresariais a assumir o deslocamento e o assentamento de famílias no estado de Mato Grosso foi liderado pelo pastor luterano Norberto Schwantes. Para esse fim, foram constituídas a Cooperativa de Colonização 31 de Março (COOPERCOL), em 1971, e a Cooperativa Agropecuária Mista Canarana Ltda. (COOPERCANA), em 1975. A experiência do grupo levou o governo Ernesto Geisel a convocar a COOPERCANA, em 1978, para resolver uma demanda de transferência de camponeses que ocupavam temporariamente um parque de exposições agropecuárias no município de Esteio, próximo a Porto Alegre (Schwantes, 1989; Santos, 2008; Lovato, 2016). Cerca de mil famílias foram transferidas para a região de TNN e NG em aproximadamente dois anos (Santos, 2008). 
O projeto de assentamento foi executado em duas etapas: Terra Nova I e II. Ao todo, foram demarcados 1.060 lotes (parcelas) de 100 ha (projeto Terra Nova I) e 50 ha (projeto Terra Nova II). Para adquirir uma propriedade, o agricultor acessava um crédito fundiário do Banco do Brasil, com prazo de quitação de 10 a 15 anos, tendo 3 a 5 anos de carência, definidos conforme a taxa de juros assumida. $\mathrm{O}$ recurso era repassado pelo Banco diretamente à COOPERCANA, como forma de reembolso pelo pagamento das terras ao INCRA e pelos investimentos em infraestrutura (topografia, instalações das agrovilas - posto de saúde, escola, armazém e pequenas casas de madeira -, rede viária e desmatamento de 10 ha nas propriedades agrícolas), financiados pelo Banco do Brasil (Schaefer, 1985; Santos, 2008).

A titulação das propriedades foi realizada inicialmente pela cooperativa e, em uma fase posterior, pelo próprio INCRA. O título referia-se a três porções de terra indissociáveis que, pelas determinações do INCRA, não podiam ser transacionadas isoladamente nem subdivididas em porções desiguais (Santos \& Santos, 2016). Tratava-se do lote destinado à exploração agrícola (100 ou 50 ha, conforme a fase do projeto), um terreno residencial localizado na agrovila mais próxima, uma chácara de cerca de 2 ha e uma área de dimensão igual à do lote localizada no condomínio de reserva legal (Santos, 2008). Cabia a cada família, com a COOPERCANA, a responsabilidade pela conservação ambiental na reserva legal (Santos \& Santos, 2016).

A Cooperativa não conseguiu cumprir com todos os compromissos assumidos e, alguns deles, como o desmatamento de 10 ha no interior das propriedades para que as famílias pudessem iniciar o plantio assim que chegassem, jamais seriam feitos
(Santos, 2008; Schaefer, 1985). Em função disso, por pelo menos dois anos, a sobrevivência das famílias dependeu da caça e pesca e de escassos recursos financeiros ou alimentos não perecíveis, financiados pelo INCRA e distribuídos pela COOPERCANA (Schwantes, 1989).

Um corte no orçamento federal, no ano de 1980, interrompeu o repasse de recursos públicos do INCRA à COOPERCANA, o que afetou diretamente as condições de vida dos assentados e provocou a debandada da maior parte dos agricultores. Os participantes da pesquisa estimam que menos de $10 \%$ daqueles que chegaram, na fase inicial da ocupação, tenham resistido às inúmeras dificuldades enfrentadas.

Nas explicações dos administradores dos projetos de colonização, o movimento de migração dos assentados se devia ao fato de eles não serem "verdadeiros lavradores", mas, sim, aventureiros, que, ao invés de trabalharem na conversão da floresta em áreas de plantio, preferiam pescar e caçar (Schwantes, 1989; Guimarães Neto, 2002; Sartre; Sebille, 2008). Uma segunda explicação considera a deficiência de infraestrutura, sobretudo de estradas, e a inoperância dos mecanismos de apoio à produção, transporte, armazenamento e comercialização de produtos agrícolas, o que provocou endividamento e falência da maioria das famílias (Santos, 2008). Adicionalmente, considera-se que o deslocamento forçado pode ter gerado certa apatia geográfica pela região amazônica que inibiu a criação de um sentimento de pertencimento (Diniz, 2003). Nesse caso, a manutenção do contato com os locais de origem, principalmente por meio de cartas, teria contribuído para o retorno de uma ampla maioria para o Rio Grande do Sul. 
Diante das falhas do projeto de colonização dirigida (executado pela cooperativa, subordinada ao INCRA) e da ampla divulgação da disponibilidade de terras a preços baixos, uma segunda onda de migração foi colocada em curso no ano de 1980, dando lugar a uma colonização espontânea (sem o aval do INCRA). Em 1981, a população local chegou a 6.957 habitantes, quantitativo que foi ampliado para 22.448 pessoas até 1991 (Ministério da Saúde, 2012).

Progressivamente, essa população ocupou, de forma aleatória, praticamente toda a área municipal, incluindo o condomínio de reservas legais, hoje denominado Quatro Reservas (Castro et al., 2002). Segundo dados do Instituto Brasileiro de Geografia e Estatística (IBGE, 2017a), atualmente, 87,4\% do território de ambos os municípios é ocupado por estabelecimento agropecuários. Em TNN, onde se localiza a área das Quatro Reservas, esse percentual chega a 95,4\% de ocupação.

A área das Quatro Reservas é formada por 86.354 hectares $(37,5 \%$ do território de TNN) (ICV, 2015), apresenta 11 comunidades rurais e é atualmente ocupada por cerca de duas mil famílias (Castro et al., 2002). A ocupação da área foi realizada principalmente por agricultores sem-terra e pequenos proprietários de terra originários do interior do Paraná. A maioria dos que residem na área atualmente adquiriu os lotes já demarcados por grileiros (especuladores). Não havia documentação da terra e a compra foi registrada somente em contratos de compra e venda, sem escritura pública.

Esse modelo de ocupação espontânea e regularização a posteriori ocupou um espaço importante no processo de colonização da fronteira agrícola amazônica (Droulers et al., 2001). De acordo com Rausch (2014), os agricultores sabiam que a lega- lidade de sua compra inicial de terra era questionável, mas, mesmo assim, permaneciam na terra, acreditando que os investimentos na propriedade favoreceriam eventuais tentativas de regularizar ou legalizar suas reivindicações no futuro. Em algumas regiões amazônicas, como no interior do estado de Rondônia, a ocupação espontânea chegava a corresponder a $40 \%$ do total de ocupações (Becker, 1990; Droulers et al., 2001).

Para Becker (1990), tratava-se de um povoamento induzido, uma vez que as propagandas e as expectativas de acesso a estímulos governamentais induziam a migração das famílias expostas aos riscos gerados pelas transformações que estavam em curso nas regiões que habitavam. Por detrás do impulso da migração estava, por conseguinte, a esperança da autonomia econômica e reprodução social da família, garantindo o futuro dos filhos na agricultura (Martins, 1997). Para grande parte das famílias, a ocupação da área das Quatro Reservas alimentava essa expectativa. Diante disso, os problemas fundiários eram secundarizados.

Além disso, como o INCRA estava legitimando a posse das terras amazônicas ocupadas espontaneamente (Becker, 1990), acreditava-se que o título das propriedades localizadas na área das Quatro Reservas não tardaria a chegar. De acordo com um dos agricultores incluídos na pesquisa, foram necessárias ao menos duas décadas para que as famílias tomassem consciência de que a regularização da posse da terra não seria possível:

O povo entrou, e deixaram o povo entrar por conta. Invadiram tudo. E o governo também não foi atrás de nada (...). Eu entrei aqui enganado, porque se eu soubesse que era reserva, não teria comprado. (...) Os vizinhos também não sabiam, ninguém sabia (...). Após o ano de 2010, as Quatro Reservas ficaram co- 
nhecidas por este nome, antes eram Posses (...). Nesse momento, as pessoas ficaram sabendo que estavam nas reservas.

Dada a irregularidade da ocupação e a ausência de ações públicas a ela associada, foram as atuações particulares das famílias de agricultores que transformaram o território, dotando-o de estradas, pontes, instituições de ensino e igrejas, entre outros. Para tanto, uma das estratégias usadas foi a organização de mutirões (ajudas mútuas). As famílias se reuniam para desenvolver atividades que atendessem a interesses individuais (conversão da floresta em áreas produtivas, preparo do solo, construção de residências etc.) e coletivos (construção de escolas, igrejas, estradas e pontes). Essa relação de ajuda, por meio da troca de favores ou da cooperação, foi fundamental para a sobrevivência da agricultura familiar no início do assentamento e para a construção do sentimento de pertencimento.

De acordo com Diniz (2003), o sentimento de "lugar" cumpria o papel de atenuar a forte tendência à migração existente entre os assentados das fronteiras agrícolas da Amazônia das décadas de 1970 e 1980. Para o autor, a vida nos assentamentos amazônicos dificultava a construção de conexões com o ambiente local, uma vez que a paisagem sofria mudanças expressivas, com as densas florestas sendo transformadas em áreas agrícolas, em curto espaço de tempo. Além disso, as comunidades geralmente eram formadas e rapidamente desmanteladas, em função da ampla mobilidade dos camponeses.

O planejamento realizado pela COOPERCANA, para a área das parcelas, definiu a demarcação de uma agrovila a cada $10 \mathrm{~km}$ (Schaefer, 1985). Trata-se, ainda hoje, de um núcleo comunitário que, na maior parte dos casos, agrega igreja, mercado, escola, área de esportes e lazer e um conjunto de residências. Essa organização foi replicada na área das Quatro Reservas, na medida em que a ocupação se expandiu e os mutirões foram se estabelecendo. Constituíram-se, como consequência, ambientes de socialização nos quais se reproduzia a cultura de festas religiosas e festas da colheita, bem como da reunião das famílias em torno de campeonatos de futebol, baralho e outros jogos. Entre outros fatores, essas formas de socialização das famílias criaram estruturas de reciprocidade, no interior das quais circulavam instrumentais imateriais (conhecimentos, informações, saberes) e/ou valores materiais (Sabourin, 2011). Eram valores que davam sentido à vida no local e que, nas circunstâncias limítrofes, tornaram a agricultura familiar possível (Radomsky \& Schneider, 2007; Sabourin, 2011).

Embora paradoxal, a presença dos madeireiros foi fundamental para a estruturação da área das Quatro Reservas. Segundo Arima et al. (2013), na Amazônia, os madeireiros eram atraídos pelos agricultores para os assentamentos espontâneos para adquirirem a madeira, em troca, transformavam em estradas as primeiras trilhas ou picadas abertas pelos agricultores na mata. Para as famílias de agricultores, a extração de madeira, muitas vezes ilegal, e sua comercialização, foi importante para a economia. O recurso obtido com a venda das toras, embora a preços significativamente inferiores ao valor de mercado, subsidiou as construções das casas e galpões, entre outros, e, em alguns casos, foi a única fonte de renda da família até a primeira colheita.

Quase nada da madeira derrubada era comercializada, uma vez que, na primeira entrada nas florestas, os madeireiros se interessavam somente pelas espécies de madeira de alto valor. Os agricultores usavam o fogo para dar fim ao grande volume 
de biomassa acumulado após as derrubadas da floresta. As queimadas eram executadas com algum nível de gestão (construção de aceiros e vigília), para impedir que o fogo encontrasse as sedes das propriedades e áreas produtivas. No entanto, as florestas adjacentes raramente eram poupadas. Como consequência, formavam-se vultosos incêndios florestais, que se estendiam por dias a fio. "O sol se tornava avermelhado por detrás das nuvens de fumaça, e as terras foram rescaldadas com as labaredas de fogo que devoravam a floresta" (Santos, 2008, p. 105).

Os incêndios, o desmatamento irregular no interior das propriedades (sem respeito a áreas de proteção permanente e reservas legais), a exploração de madeira e a abertura de estradas contribuíram com a progressiva perda das florestas, restando, hoje, apenas pequenas porções isoladas de floresta, que, somadas, totalizam não mais que $15 \%$ da cobertura do território (INPE, 2017). Dados compilados pelo Instituto Centro de Vida (ICV, 2016) demonstram que, em TNN, a maior parte das florestas foi removida até o ano de 2001 (67,7\%) (Figura 3). Os fragmentos florestais remanescentes estão localizados predominantemente nos topos dos morros (Figuras 3 e 4 ).

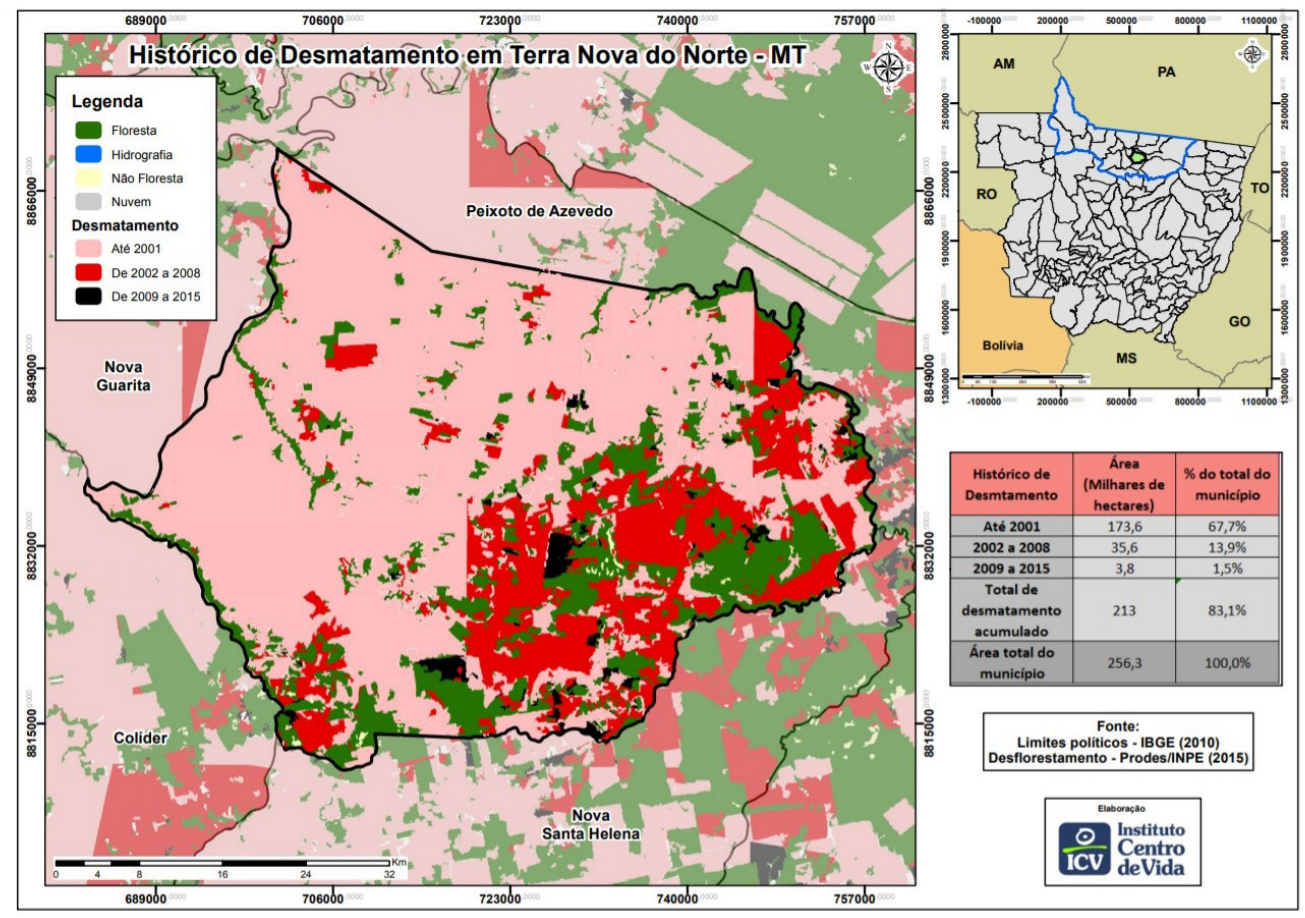

FIGURA 3 - Histórico do desmatamento no município de Terra Nova do Norte - MT.

FONTE: ICV (2016). 


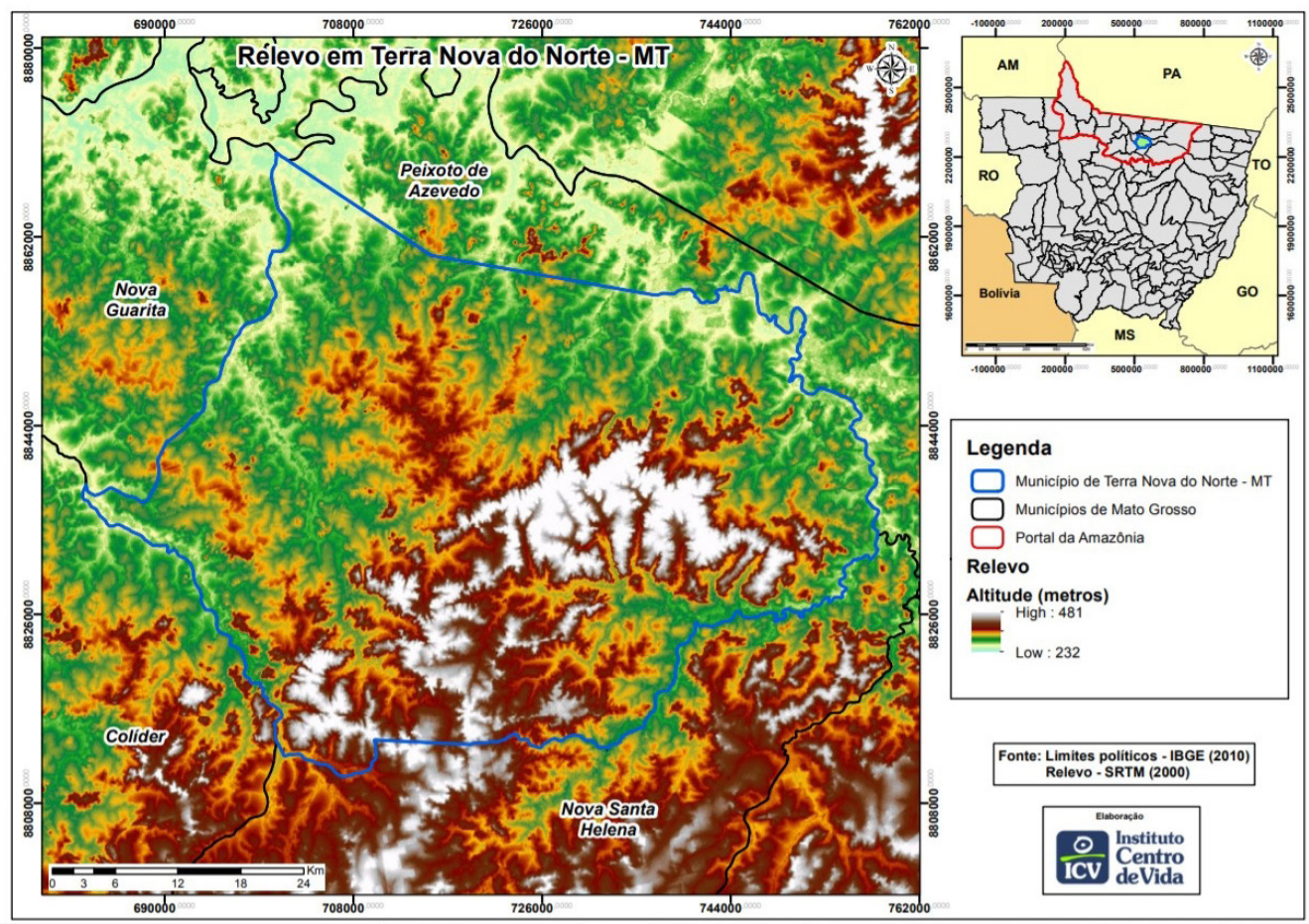

FIGURA 4 - Relevo do município de Terra Nova do Norte - MT.

FONTE: ICV (2016).

$\mathrm{O}$ intenso processo de desmatamento afetou o ecossistema local. As nascentes hidrográficas foram comprometidas, resultando na perda do fluxo de água e, em algumas propriedades, na seca dos igarapés durante o período de estiagem, afetando, inclusive, o fornecimento de água para o gado. Em outras propriedades, o desmatamento das áreas de proteção permanente provocou o assoreamento dos corpos d'água. De acordo com participantes da pesquisa, alguns lugares, onde a travessia dependia do uso de barco, são atravessados a pé nos dias de hoje.

As mudanças na paisagem foram significativas. A área de floresta, que cedeu lugar às lavouras brancas (milho, arroz, feijão etc.), em um primeiro momento, a partir dos anos 2000, foi vertiginosamente transformada em pastagem. Em 2007, 74,3\% das áreas com atividades agropecuárias estavam cobertas por capim (variedades diferentes de Brachiaria brizantha e, em menor escala, Panicum maximum (mombaça)). Os remanescentes de áreas usadas na agricultura (produção de cereais, frutas, hortaliças e criação de pequenos animais etc.) não passavam de 3,3\% em TNN e 8,2\% em NG (Bernasconi et al., 2009).

Entre os principais determinantes da ampla especialização da pecuária leiteira, na primeira década 
dos anos 2000, está a modalidade de crédito (PRONAF A) aplicada para a agricultura familiar, cujas especificidades regionais definiam a adoção de um pacote de crédito simples, que incluía apenas vacas, cercas e pastagem (Sabourin, 2006; Moreira, 2014). Estudos desenvolvidos na região demonstram que o Programa apresenta várias deficiências na aplicação e gestão (Sabourin, 2006; Eiró \& Tricaud, 2010; Moreira, 2014; Oliveira \& Bergamasco, 2014). No entanto, por se tratar de uma possibilidade de investimento que, à época de sua disseminação, coincidiu com a demanda pela redução de custos e mão de obra na produção e perdas sazonais, o instrumento foi fundamental para o fortalecimento da agricultura familiar.

A publicação da resolução $n^{0} 3.545$, de 29 de fevereiro de 2008, do Banco Central do Brasil (BACEN, 2008), pôs fim no acesso dos agricultores de TNN e NG a financiamentos públicos. Isso ocorreu porque os bancos passaram a exigir a apresentação de documento comprobatório de regularidade ambiental do imóvel.

Os principais problemas enfrentados pelos agricultores para a regularização das propriedades está o excesso de desmatamento de reservas legais, em desobediência ao que prevê a Lei $n^{\circ} 12.651$, de 25 de maio de 2012 (novo Código Florestal brasileiro) (Brasil, 2012). Uma ilegalidade que prejudica a efetivação do licenciamento ambiental dos lotes, por parte dos agricultores das parcelas. Ademais, no caso dos agricultores da área das Quatro Reservas, a negação do crédito está relacionada à ausência de titulação da propriedade, que é considerada ilegítima, uma vez que as terras ocupadas pertencem legalmente aos proprietários da área das parcelas.

A problemática foi trazida à tona por uma série de medidas de contenção do desmatamento e de adequação ambiental, colocadas em curso por meio da parceria entre o Ministério do Meio Ambiente e o INCRA, no início dos anos 2000. Um movimento que colocou o Código Florestal em evidência e pressionou os agricultores a legalizarem a sua situação. Até então, segundo um dos agricultores da área das parcelas:

podia abrir até o lote inteiro. Não estava protegido por lei, podia abrir. (...) Era só derrubar, porque tinha a metade lá. Pagava até imposto sobre o mato [na área das Quatro Reservas].

No entanto, ainda que tenham tomado consciência da necessidade de adequar-se à legislação, os agricultores da área das parcelas, sozinhos, não conseguem resolver o problema. Isso porque o processo de licenciamento ambiental rural, determinado pelo Conselho Nacional do Meio Ambiente (CONAMA), é de responsabilidade do INCRA. A instituição assumiu a missão, em 2003, por meio de um Termo de Ajustamento de Conduta (TAC), mas não a cumpriu (Le Tourneau \& Bursztyn, 2010). Até os dias atuais, os agricultores continuam sem o referido licenciamento.

A negação do crédito tem produzido uma perda significativa em termos de melhoraria da qualidade do leite, uma vez que faltam recursos para investir em instalações, resfriadores, ordenhadeiras e produção de silagem. Segundo os agricultores, são melhorias importantes, pois reduzem o risco de perda de cabeças de gado durante o período de estiagem, ampliam a sustentabilidade da prática agropecuária, uma ação que tem sido promovida pela COOPERNOVA, e aumentam o valor comercial do litro de leite. 
Além disso, segundo Eiró \& Tricaud (2010), em assentamentos rurais do norte de Mato Grosso, verifica-se que a punição implica no aumento do desmatamento no interior da propriedade. Isso porque, com o congelamento de créditos - que serviriam de incentivo à recuperação da reserva legal -, perde-se um importante mecanismo de controle do desmatamento, regulação do mercado ou assistência técnica. A demora na titulação das propriedades tem efeito similar, uma vez que gera incertezas que favorecem a exploração de recursos naturais (Calandino et al., 2012).

Diante das complicações decorrentes das restrições de acesso ao crédito, formou-se um grupo de representantes que se uniu a lideranças da cooperativa e representantes políticos da região para reivindicar soluções ao poder público estadual e federal. Esse movimento levou à aprovação da Lei $n^{0} 8.680$, de 13 de julho de 2007 (Assembleia Legislativa do Estado de Mato Grosso, 2007), que trata da compensação das reservas legais de TNN e NG em outros municípios. Para tanto, o governo do estado sancionou a ampliação dos limites de duas reservas ambientais, a Estação Ecológica do Rio Roosevelt e a Reserva Extrativista Guariba-Roosevelt, ambas localizadas nos municípios de Aripuanã e Colniza, no noroeste do estado. Com a permuta de terras, as reservas legais correspondentes às propriedades da área das parcelas seriam deslocadas para as duas reservas ambientais do noroeste. Em contrapartida, a área das Quatro Reservas ficaria livre para dar início ao processo de titulação das propriedades.

Ao efetuar a compensação, o estado incentivou os agricultores a procederem a regulação ambiental de suas propriedades. Para esse fim, em 2011, os agricultores de TNN foram beneficiados por um projeto desenvolvido por meio de uma parceria entre instituições públicas, privadas e o terceiro setor (Santos \& Santos, 2016). A grande maioria dos assentados providenciou o Cadastro Ambiental Rural (CAR) e o Georreferenciamento do Imóvel Rural (GeoIncra). As orientações que o grupo recebeu foram que essa iniciativa traria segurança jurídica aos proprietários.

Apesar disso, uma decisão judicial de dezembro de 2016 (Ministério Público do Estado de Mato Grosso, 2016) anulou os títulos de propriedade concedidos aos assentados, no interior das Quatro Reservas, pelo Instituto de Terras de Mato Grosso (INTERMAT), defendendo a inconstitucionalidade da Lei n ${ }^{\circ}$. 8.680/2007. A principal alegação da Procuradoria Geral de Justiça foi que a exploração da área das Quatro Reservas por terceiros, seja por fatores legítimos ou não, contribuiu para a degradação de um patrimônio público essencial à sadia qualidade de vida. Em síntese, a instituição defendeu que os ambientes dessas reservas legais devem ser necessariamente assegurados e protegidos, tendo em vista as determinações do Código Florestal (Ministério Público do Estado de Mato Grosso, 2016).

Em 2015, o Legislativo havia feito uma nova tentativa de regularização da situação, aprovando a Lei Estadual n ${ }^{\circ}$. 10.261 (Assembleia Legislativa do Estado de Mato Grosso, 2015), a qual disciplinava a regularização fundiária da área das Quatro Reservas, novamente a partir do deslocamento das reservas legais de Terra Nova e Guarita para as áreas da Reserva Extrativista Guariba-Roosevelt e da Estação Ecológica do Rio Roosevelt. A Lei foi igualmente considerada inconstitucional pela Procuradora Geral de Justiça do Estado, argumentando, desta vez, que as reservas de Aripuanã e Colniza são incapazes de compensar o passivo ambiental das 
Quatro Reservas em virtude do avançado grau de desmatamento na área que seria permutada.

Em meio às turbulências, uma parcela importante dos agricultores se organizou, com apoio de instituições públicas e do terceiro setor, para criar oportunidades de renda e, na medida do possível, adequar as propriedades rurais à legislação ambiental. Esse processo levou à emergência de pelo menos quatro frentes. A primeira transforma em oportunidade de uso agrícola a restauração florestal de áreas de proteção permanente (cursos d'água e nascentes). Formam-se, assim, sistemas agroflorestais (SAFs) voltados à conservação de solo e água e à produção de frutas e café em pomares (Andrade, 2007; Feistauer, 2012; De Paula et al., 2019). Na perspectiva mais recente, parte desses sistemas são transformados em agrossilvipastoris, integrando animais bovinos, pastagem e árvores frutíferas nativas, como o pequi (Caryocar sp.), por exemplo.

Desdobram-se, desse movimento, a criação da Associação da Agricultura Familiar do Portal da Amazônia (AAFPA), realizada pelas mulheres que atuam no processamento e comercialização de pequi e organização de uma festa anual da colheita da fruta. Como também a organização de feiras agroecológicas semanais, realizada igualmente pelas mulheres para facilitar a comercialização da produção agrícola, pães, doces e artesanatos.

A segunda frente reúne um movimento de qualificação e certificação dos produtos orgânicos, que teve como embrião a Cooperativa de Agricultores Agroecológicos de Terra Nova do Norte (COOPERAGREPA) (Sabourin, 2012). Embora as atividades da COOPERAGREPA tenham sido encerradas em 2011, de acordo com Moreira (2014), a iniciativa incentivou práticas agrícolas ecológicas a partir do suporte, treinamento técnico, aconselhamento sobre a criação de redes de produção-marketing-consumo e assistência na certificação orgânica.

A terceira frente caracteriza-se pela participação dos agricultores em uma Rede de Sementes, organizada pelo Instituto Ouro Verde (IOV). Trata-se de uma estratégia que arranja o setor de sementes florestais nativas brasileiro, formado por sete redes. Em TNN e NG, são ao todo 33 famílias de agricultores que participam da coleta e armazenamento de sementes, as quais são distribuídas a instituições que desenvolvem projeto de restauração florestal e ao mercado externo (Andrade, 2018).

Em síntese, esse conjunto de iniciativas recentes dá fôlego às famílias, enquanto assistem ao crescimento das restrições impostas pela ilegalidade da ocupação das propriedades. Trata-se de um processo novo, que pode gerar autonomia das famílias e comunidades e a revalorização da agricultura familiar entre os consumidores. Se irá se consolidar, o tempo dirá.

\section{Considerações finais}

O objetivo do estudo foi compreender as dificuldades geradas pelo modelo de ocupação da fronteira agrícola em TNN e NG e as estratégias usadas pelos agricultores familiares para superá-las. Nesse sentido, o que se extrai dos dados coletados é que as dificuldades vivenciadas pelos agricultores que ocuparam os municípios de TNN e NG pouco se distinguem da realidade vivida pelos milhares de brasileiros que migraram para a Amazônia em busca de terra e da reprodução social de suas famílias na agricultura. Pode-se citar, como principais determinantes desse processo, a ausência do Estado, 
especialmente em termos de ações sociais e econômicas e de comando e controle ambiental.

Os problemas se tornam mais visíveis na medida em que avança o aprimoramento da gestão pública. Assim, por exemplo, os agricultores que conseguiam acessar crédito agrícola, mesmo em situação ambiental e fundiária irregular, a partir dos anos 2000, esbarram no endurecimento das restrições. Nessa perspectiva, são as pressões nacionais e internacionais em torno da questão ambiental na Amazônia que pesam sobre a agricultura familiar, em um contexto de vulnerabilidade historicamente construído.

A trajetória da agricultura familiar na região não é linear. Ao contrário, várias transformações são colocadas em curso após os períodos de crise, gerando sucessivas etapas de reemergência da agricultura familiar, que produzem fases de resiliência. Entre as principais estratégias usadas pelos agricultores para chegar a esse patamar, cabe destacar o reforço trazido pela mobilização dos agricultores, por meio da reprodução da cultura dos mutirões (ajuda-mútuas) e a organização de festas e reuniões, entre outras estratégias de reciprocidade e organização social. Sem entrar no mérito da questão, foram igualmente importantes as alianças construídas com madeireiros e as articulações com representantes legais, com quem, atualmente, os agricultores buscam apoio para a regularização fundiária.

A nova fase que se inicia, com a execução de projetos que aliam a economia, a restauração florestal e organização social, apresenta perspectivas positivas de desenvolvimento, sobretudo quando se leva em conta a sustentabilidade dos processos. Entretanto, ainda há muito o que avançar, especialmente no que se refere à construção da autonomia dos sujeitos e seus grupos.

\section{Agradecimentos}

Os autores agradecem ao Fundo Amazônia, que viabilizou os recursos para a pesquisa, por meio do BNDES, e ao Instituto Ouro Verde (IOV) e seus técnicos, pelo apoio de campo.

\section{Referências}

Andrade, J. Implantação do pagamento por serviços ecossistêmicos no território portal da amazônia: uma análise econômico-ecológica. Campinas, Dissertação (Mestrado em Desenvolvimento Econômico) - UNICAMP, 2007.

Andrade, M. Da semente à comercialização: a produção de sementes florestais no Território do Portal da Amazônia. São Paulo, Trabalho de Conclusão de Curso (Graduação em Engenharia Florestal e Ciências Agrárias) - USP, 2018.

Arcemy, M. Geografia de Mato Grosso. Rondonópolis: EdUFMT, 2007.

Arima, E. Y.; Walker, R. T.; Souza, C.; Pereira, R.; do Canto, O. Spontaneous colonization and forest fragmentation in the Central Amazon Basin. Annals of the Association of American Geographers, 103(6), 1485-1501, 2013. doi: 10.1080/00045608.2013.834231

Assembleia Legislativa do Estado de Mato Grosso. Lei $n^{\circ}$ 8.680. Dispõe sobre a ampliação das áreas da Estação Ecológica Rio Roosevelt e da Reserva Extrativista Guariba-Roosevelt. Cuiabá, DOE de 13/072007.

Assembleia Legislativa do Estado de Mato Grosso. Lei $n^{\circ}$ 10.261. Disciplina a regularização fundiária dos ocupantes da área denominada 4 Reservas e dá outras providências. Cuiabá: DOE de 22/01/2015.

BACEN - Banco Central do Brasil. Resolução $n^{\circ} 3.545$, de 29 de fevereiro de 2008. Brasília: DOU de 03/03/2008.

Becker, B. K. Significância contemporânea da fronteira: uma interpretação geopolítica a partir da Amazônia Brasileira. In: Aubertin, C. (Ed.). Fronteiras. Brasília: Editora UnB, 1988. p. 60-89. 
Becker, B. K. Estratégia do Estado e povoamento espontâneo na expansão da fronteira agrícola em Rondônia: integração e conflito. In: Becker, B. K.; Miranda, M.; Machado, L. O. (Eds.). Fronteira Amazônica. Brasília: Editora Universidade de Brasília, 1990. p. 147-164.

Bernasconi, P.; Santos, R. R.; Rodrigues, J. A. AAI Avaliação ambiental integrada: território portal da Amazônia. Alta Floresta: ICV, 2009. Disponível em: < https://www.icv.org. br/publicacao/aai-avaliacao-ambiental-integrada-do-territorio-portal-da-amazonia/> . Acesso em: set. 2013.

Brasil. Lei n ${ }^{\circ}$ 12.651, de 25 de maio de 2012. Brasília: DOU de 28/05/2012.

Brasil. Decreto No 9.064, de 31 de maio de 2017. Brasília: DOU de 31/05/2017.

Browder, J.; Pedlowski, M. A.; Walker, R.; Wynne, R. H.; Summers, P. M.; Abad, A.; Becerra-Cordoba, N.; Mil-Homens, J. Revisiting theories of frontier expansion in the brazilian amazon: a survey of the colonist farming population in Rondônia's post-frontier, 1992-2002. World Development, 36(8), 1469-1492, 2008. doi: 10.1016/j. worlddev.2007.08.008

Calandino, D.; Wehrmann, M.; Koblitz, R. Contribuição dos assentamentos rurais no desmatamento da Amazônia: um olhar sobre o Estado do Pará. Desenvolvimento e Meio Ambiente, 26(29), 2012. doi: 10.5380/dma.v26i0.26017

Castro, S.; Barrozo, J.; Covezzi, M.; Preti, O. A colonização oficial em Mato Grosso: a nata e a borra da sociedade. Cuiabá: EdUFMT, 2. ed., 2002.

Coy, M. Différenctiation et transformation de l'espace ao Nord du Mato Grosso. Contribuition à un modèle dynamique des fronts pionniers en Amazonie brésilienne. In: Albaladejo, C.; Tulet, J.-C. (Eds.). Les fronts pionniers de l'Amazonie brésilienne: la formation de nouveaux territoires. Paris: L'Harmattan, 1996. p. 103-27.

De Paula, R. P.; Sais, A. C.; De Oliveira, R. E.; Olival, A. D. A. Sistemas agroflorestais na paisagem rural em Terra Nova do Norte-MT: métricas espaciais no auxílio das políticas de conservação ambiental em áreas de produção familiar. Desenvolvimento e Meio Ambiente, 52, 175-193, 2019. doi: 10.5380/dma.v52i0.61729
Diniz, A. A dimensão qualitativa da mobilidade humana na fronteira agrícola de Roraima. Cadernos de Geografia, 13(21), 44-59, 2003.

Droulers, M.; Le Tourneau, F.-M.; Machado, L. Conflits d'usage de l'espace au Rondônia (Amazonie brésilienne). Cybergeo, 194, 2001. doi: 10.4000/cybergeo. 3772

Eiró, F.; Tricaud, S. Gestão Ambiental de Assentamentos na Amazônia Estudo de caso do Projeto de Assentamento Juruena. In: Anais do V Encontro Nacional da Associação Nacional de Pós-Graduação e Pesquisa em Ambiente e Sociedade (ANPPAS). Florianópolis, 4 de out., 2010. Disponível em: < http://www.anppas.org.br/encontro5/cd/ artigos/GT2-347-620-20100903112825.pdf $>$. Acesso em: abr. 2020.

EMBRAPA - Empresa Brasileira de Pesquisa Agropecuária. Sistema brasileiro de classificação de solos. Rio de Janeiro: Embrapa Solos, 1999. Disponível em: < https://www. embrapa.br/solos/sibcs>. Acesso em: abr. 2020.

Escada, M. I. S.; Vieira, I. C. G.; Kampel, S. A.; Araújo, R.; Veiga, J. B. da; Aguiar, A. P. D.; Veiga, I.; Oliveira, M.; Pereira, J. L. G.; Carneiro Filho, A.; Fearnside, P. M.; Venturieri, A.; Carriello, F.; Thales, M.; Carneiro, T. S. G.; Monteiro, A. M. V.; Câmara, G. Processos de ocupação nas novas fronteiras da Amazônia: o interflúvio do Xingu/ Iriri. Estudos Avançados, 19(54), 9-23, 2005. doi: 10.1590/ S0103-40142005000200002

Fearnside, P. M. Brazil's Amazon settlement schemes. Habitat International, 8(1), 45-61, 1984. doi: 10.1016/01973975(84)90027-4

Feistauer, D. Adequação à legislação ambiental de pequenas propriedades rurais conduzidas em sistema orgânico ou convencional no Território Portal da Amazônia - Mato Grosso. Florianópolis, Dissertação (Mestrado em Agroecossistemas) - UFSC, 2012.

Foucher, M. Fronts et frontières: un tour du monde géopolitique. Ed. Paris: Fayard, 1991.

Franco da Silva, C. A.; Bampi, A. C. Regional dynamics of the brazilian Amazon: between modernization and land conflicts. Cuadernos de Geografia: Revista Colombiana de Geografia, 28(2), 340-356, 2019. doi: 10.15446/rcdg. v28n2.72872. 
Gondim, S. Grupos focais como técnica de investigação qualitativa: desafios metodológicos. Paidéia, 12(24), 149-161, 2003.

Guimarães Neto, R. B. A lenda do ouro verde: política de colonização no Brasil contemporâneo. Cuiabá, MT [Brasília, Brazil]: UNICEN Publicações; UNESCO, 2002.

IBGE - Instituto Brasileiro de Geografia e Estatística. Censo demográfico 2000. Rio de Janeiro: IBGE, 2000. Disponível em: <www.ibge.gov.br>. Acesso em: out. 2017.

IBGE - Instituto Brasileiro de Geografia e Estatística. Mapa de vegetação do Brasil, 2004. Disponível em: <ftp://geoftp. ibge.gov.br/informacoes_ambientais/vegetacao/mapas/ brasil/vegetacao>.pdf>. Acesso em: abr. 2020

IBGE - Instituto Brasileiro de Geografia e Estatística. Censo Demográfico 2010, 2010. Disponível em: $<$ http://www.cidades.ibge.gov.br/xtras/perfil.php?lang=\&codmun=510025\&search=mato-grosso|alta-floresta $>$. Acesso em: out. 2015.

IBGE - Instituto Brasileiro de Geografia e Estatística. Cidades@, 2017a. Disponível em: <www.cidades.ibge.gov. br/\$. Acesso em: fev. 2017.

IBGE - Instituto Brasileiro de Geografia e Estatística. Censo Agro 2017, 2017b. Disponível em: <https://censos.ibge. gov.br/agro/2017/templates/censo_agro/resultadosagro/pdf/ agricultura_familiar.pdf $>$. Acesso em: out. 2019.

ICV - Instituto Centro de Vida. Conhecendo municípios do Portal da Amazônia - Terra Nova do Norte. Alta Floresta: Instituto Centro de Vida, 2016. Disponível em: < https:// www.icv.org.br/drop/wp-content/uploads/2016/10/Atlas-Terra-Nova-do-Norte.pdf>. Acesso em: abril 2020.

ICV - Instituto Centro de Vida. Situação fundiária no municipio de Terra Nova do Norte (MT). Cuiabá: Instituto Centro de Vida, 2015. Disponível em: < https://www.icv.org. $\mathrm{br} / \mathrm{drop} / \mathrm{wp}$-content/uploads/2016/06/An\%C3\%A1lise_fundi\%C3\%A1ria_TerraNova.pdf>. Acesso em: dez. 2017.

INPE - Instituto Nacional de Pesquisas Espaciais. Desflorestamento nos Municípios da Amazônia Legal para o ano de 2017, 2017. Disponível em: <http://www.dpi.inpe.br/ prodesdigital/prodesmunicipal.php $>$. Acesso em: jun. 2019.

Joanoni Neto, V. Fronteiras da crença: ocupação do norte de Mato Grosso após 1970. Cuiaba: EdUFMT; Carlini \&
Caniato Editorial, 2007.

Kitzinger, J. Focus group research: using group dynamics to explore perceptions, experiences and understandings. In: Holloway, I. (Ed.). Qualitative research in health care. Maidenhead: Open University Press, 2005. p. 56-70.

Le Borgne-David, A. Les migrations paysannes du sud-Brésil vers $L$ 'Amazonie: le salariat plutôt que la malaria. Paris: Editions L'harmattan, 1998.

Le Tourneau, F.-M.; Bursztyn, M. Assentamentos rurais na Amazônia: contradições entre a política agrária e a política ambiental. Ambiente \& Sociedade, 13(1), 111-130, 2010. doi: 10.1590/S1414-753X2010000100008

Le Tourneau, F.-M. Is Brazil now in control of deforestation in the Amazon? Cybergeo: European Journal of Geography, Environnement, Nature, Paysage, 769, 2016. doi: 10.4000/ cybergeo. 27484 .

Léna, P. Expansion de la frontière économique, accès au marché et transformation de l'espace rural en Amazonie brésilienne. Cahiers des Sciences Humaines, 28(4), 579-601, 1992.

Lovato, D. M. C. O projeto Terra Nova em Mato Grosso no contexto da fronteira capitalista: um estudo de caso. Revista de Ciências Sociais do Norte de Mato Grosso, 5(2), 25-41, 2016.

Martins, J. de S. Fronteira: a degradação do outro nos confins do humano. São Paulo: Hucitec, 1997.

Ministério da Saúde. DATASUS, 2012. Disponível em: $<$ http://tabnet.datasus.gov.br/cgi/tabcgi.exe?ibge/cnv/popmt.def $>$. Acesso em: abr. 2020.

Ministério Público do Estado de Mato Grosso. Sentença. Tribunal de Justiça de Mato Grosso, 2016. Disponível em: $<$ http://www.tjmt.jus.br/intranet.arq/downloads/Imprensa/ NoticiaImprensa/file/2017/01\%20-\%20Janeiro/04\%20-\%20 Decis\%C3\%A3o\%20Terra\%20Nova\%20do\%20Norte. pdf>. Acesso em: dez. 2017.

Moreira, I. S. Gouvernance territoriale du développement rural au Brésil. Le cas d'un front pionnier: "Portal da Amazônia". Toulouse, FR, Thèse (Doctorat en Géographie et Aménagement) - Université Toulouse II, 2014. 
Oliveira, A.; Bergamasco, S. M. P. P. Fortalecimento da agricultura familiar: uma análise do PRONAF no projeto de assentamento São Pedro, Paranaíta, MT. Retratos de Assentamentos, 17, 205-224, 2014.

Oliveira, A. U. A agricultura camponesa no Brasil. São Paulo: Contexto, 1991.

Oliveira, L. R.; Bursztyn, M. Conflitos socioambientais nas reservas legais em bloco: o caso do PA Margarida Alves, em Rondônia. In: Theodoro, S. H. (Ed.). Mediação de conflitos socioambientais. Rio de Janeiro: Garamond, 2005. p. 91-106.

Radomsky, G.; Schneider, S. Nas teias da economia: o papel das redes sociais e da reciprocidade nos processos locais de desenvolvimento. Sociedade e Estado, 22(2), 249-284, 2007. doi: 10.1590/S0102-69922007000200003

Rausch, L. Convergent agrarian frontiers in the settlement of Mato Grosso, Brazil. Historical Geography, 42, 276-297, 2014.

Sabourin, E. Interação entre políticas públicas e dinâmicas locais da agricultura familiar do Território do Portal da Amazônia - Mato Grosso. Montpellier: CIRAD, 2006.

Sabourin, E. Camponeses do Brasil: Entre a troca mercantil e a reciprocidade. Tradução: Milani, L. Rio de Janeiro: Garamond, 2009.

Sabourin, E. Teoria da reciprocidade e sócio-antropologia do desenvolvimento. Sociologias, 13(27), 24-51, 2011. doi: 10.1590/S1517-45222011000200003

Sabourin, E. A Construção social dos mecanismos de qualificação e certificação entre reciprocidade e troca mercantil. REDD - Revista Espaço de Diálogo e Desconexão, 4(2), 83-104, 2012.

Santos, J. Programa de Colonização Terranova. In: Barrozo, J. C. (Ed.). Mato Grosso: Do sonho à utopia da terra. Cuiabá: EdUFMT, p. 97-140, 2008.

Santos, V.; Santos, S. O cadastro ambiental rural e os desafios para sua efetiva implementação no município de Terra Nova do Norte - MT. In: Anais do $6^{o}$ Simpósio de Geotecnologias no Pantanal. Cuiabá, 22 out., 2016. Disponível em: <https://www.geopantanal.cnptia.embrapa.br/2016/cd/ pdf/p10.pdf $>$. Acesso em: abr. 2020.
Sartre, X. A. de; Sebille, P. Diversidade dos itinerários migratórios dos colonos de uma frente pioneira amazônica. Confins, 4, 2008. doi: 10.4000/confins.4403.

Schaefer, J. R. As migrações rurais e implicações pastorais: Um estudo das migrações campo-campo do Sul do país em direção ao Norte de Mato Grosso. São Paulo: Edições Loyola, 1985.

Schittini, G. De M.; Franco, J. L. De A.; Drummond, J. A. Expansão da fronteira de recursos naturais e Unidades de Conservação da natureza na área da influência da BR-163. In: Franco, J. L. De A.; Drummond, J. A.; Tavares, G. G. (Eds.). História ambiental: fronteiras, recursos naturais e conservação da natureza. Rio de Janeiro: Garamond, 2012. p. 119-146.

Schwantes, N. Uma cruz em Terra Nova. São Paulo: Scritta Oficina Editorial, 1989.

Trad, L. A. B. Grupos focais: conceitos, procedimentos e reflexões baseadas em experiências com o uso da técnica em pesquisas de saúde. Physis: Revista de Saúde Coletiva, 19(3), 2009. doi: 10.1590/S0103-73312009000300013

Wanderley, M. N. Agricultura familiar e campesinato: rupturas e continuidade. Estudos Sociedade e Agricultura, 21, 42-61, 2003.

Wanderley, M. N. O mundo rural como espaço de vida: Reflexões sobre a propriedade da terra, agricultura familiar e ruralidade. Porto Alegre: Editora da UFRGS, 2009.

Weller, W. Grupos de discussão na pesquisa com adolescentes e jovens: aportes teórico-metodológicos e análise de uma experiência com o método. Educação e Pesquisa, 32(2), 241-260, 2006. doi: 10.1590/S1517-97022006000200003

Yakura, E. K. Charting time: timelines as temporal boundary objects. The Academy of Management Journal, 45(5), 956-970, 2002. doi: 10.2307/3069324 